\title{
Home Management of the Device Detected Atrial Fibrillation during COVID-19 Pandemic: A Case Report
}

\author{
Idaliya Rakhimova ${ }^{1}$ D, Talgat Khaibullin ${ }^{1}$ (D), Yerbol Smail ${ }^{1}$ (D), Zhanar Urazalina ${ }^{1}$, Vitaly Kovalchuk $^{2}$ (D), Ayan Abdrakhmanov , $^{3}$ \\ ${ }^{1}$ Department of Cardiology and Interventional Arrhythmology, Semey Medical University, Kazakhstan; ${ }^{2}$ Rehabilitation Centre, \\ Hospital No 38 named after N.I. Semashko, St. Petersburg, Russia; ${ }^{3}$ Department of Interventional Arrhythmology, National \\ Scientific Cardiac Surgery Center, Astana, Kazakhstan
}

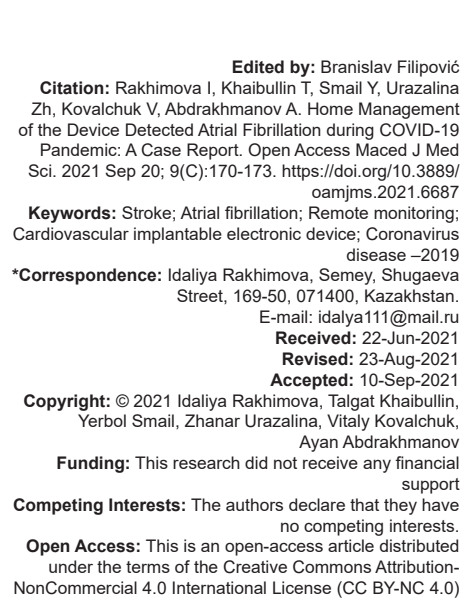

\section{Introduction}

Stroke is an avoidable complication of atrial fibrillation (AF). Subclinical $A F$, as a finding in the records of implanted cardiac devices, has the same implications as clinical AF [1]. In recent years, there has been an increase in patients with implanted heart devices. A large proportion of these patients are patients with chronic heart failure (HF). Usually, these are older people with concomitant pathology [2], [3].

Hospital visits by such patients during the coronavirus disease -2019 (COVID-19) pandemic may have poor outcomes. This cohort of patients is more severely affected and at risk of death if infected [4]. Therefore, remote management of such patients is now the most appropriate. Timely prescription of anticoagulant drugs, after assessing the risk of stroke, may prevent thromboembolic complications such as stroke [5], [6].

The classification of AF includes permanent and non-permanent forms. In the case when AF is permanent, it is not difficult to register it using a routine 12-channel ECG. Documentation of paroxysmal or persistent forms of AF presents some difficulties, due to the possibility of its asymptomatic course and short-term nature [1]. In this situation, implanted heart devices may be beneficial, allowing long-term monitoring of the atrial rhythm. It should be noted that patients with implanted cardiac devices take antiplatelet therapy to prevent thromboembolic complications. The detection of AF in them will allow for more effective prevention of thrombosis by prescribing anticoagulants [7].

We present a case with completely remote management of a patient with $\mathrm{CHF}$ and new-onset AF. 


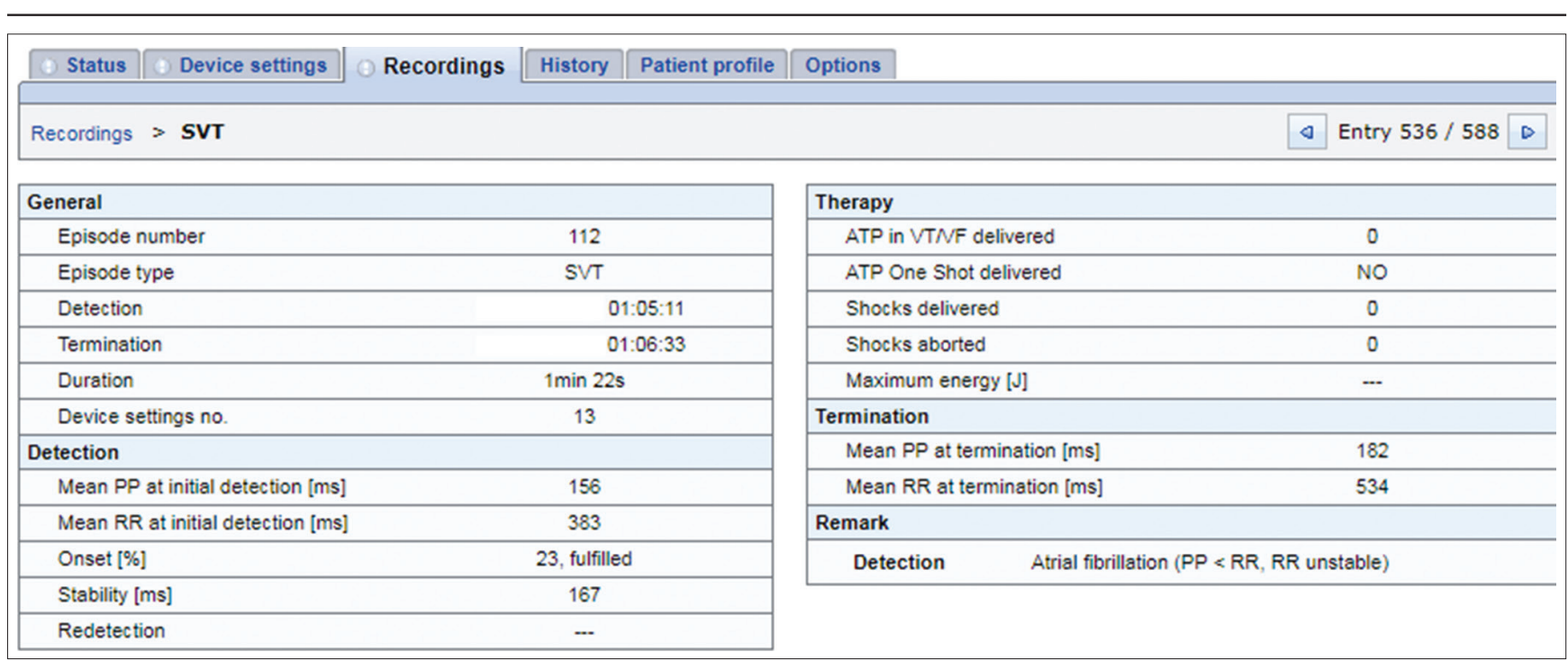

Figure 1: Report of device detected atrial fibrillation

\section{Patient Presentation}

A 56-year-old man presented to the clinic with shortness of breath when climbing the second floor, moderate non-specific fatigue, general weakness, and a decrease in exercise tolerance.

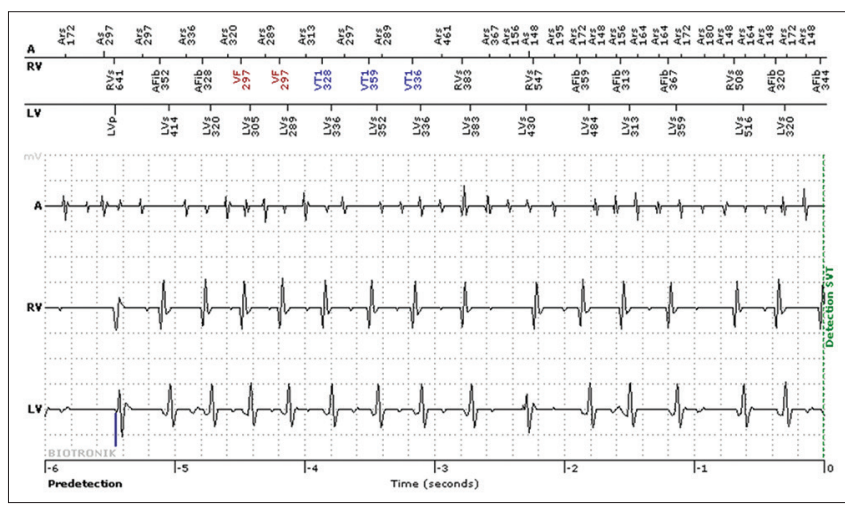

Figure 2: IEGM of device detected atrial fibrillation

Medical history included arterial hypertension for 10 years with maximum BP 200/100 mm Hg, myocardial infarction 8 years before, right coronary artery stenting, circumflex coronary artery bypass grafting, and mammary coronary artery bypass grafting of the anterior interventricular branch.

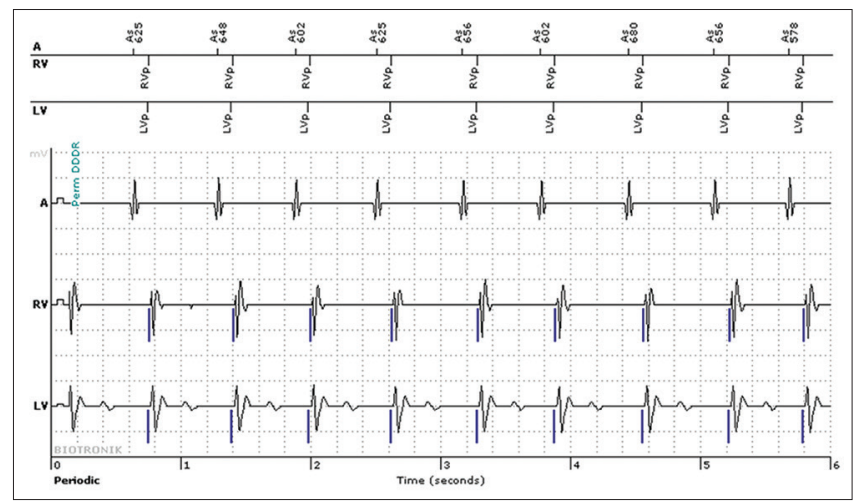

Figure 3: IEGM after treatment
Physical examination on admission showed obesity with body mass index $-35.0 \mathrm{~kg} / \mathrm{m}^{2}$ no edema. Patient's pulse was regular with an average rate of 76 beats $/ \mathrm{min}$. Blood pressure on the both sides was $90 / 60 \mathrm{~mm} \mathrm{Hg}$. The patient received standard treatment for HF for at least 3 months (ACEI, beta blockers, MR antagonists, and loop diuretics) in individually selected adequate doses.

\section{Initial work up}

ECG on admission, sinus rhythm with a heart rate of 81 beats $/ \mathrm{min}, \mathrm{QRS} 150 \mathrm{~ms}$. LBBB. Biochemical blood test cholesterol $-5.25 \mathrm{mmol} / \mathrm{l}$, triglycerides - 1.18 $\mathrm{mmol} / \mathrm{l}$, LDL chol - $3.25 \mathrm{mmol} / \mathrm{l}$, HDL chol - $1.93 \mathrm{mmol} / \mathrm{l}$, glucose - $100.6 \mathrm{mg} / \mathrm{dl}, \mathrm{Na}-138 \mathrm{mmol} / \mathrm{L}, \mathrm{K}-4.3 \mathrm{mmol} / \mathrm{L}$, and Pro-BNP-1512 pg/ml $6 \mathrm{~min}$ walk test $-320 \mathrm{~m}$. Echo showed dilation of all heart chambers, diffuse hypokinesis of the walls with akinesis of the apical, middle anterior LV segments, as well as hypokinesis of the basal, middle apical, and anterior septal segment of the LV. Global myocardial contractility was reduced. The ejection fraction was reduced to $35 \%$. Moderate mitral and mild tricuspid regurgitation was also identified. RV function is reduced. Doppler ultrasonography of the vessels of the brachiocephalic trunk and legs revealed atherosclerosis of the carotid arteries without hemodynamic disturbances, and hypoplasia of the right vertebral artery. Arteries and veins of both legs are patent.

\section{Diagnosis and management}

According to indications for cardiac resynchronization therapy in patients in sinus rhythm from ESC Guidelines, CRT is recommended in chronic $\mathrm{HF}$ patients and left ventricular ejection fraction $\leq 35 \%$ that remain in NYHA functional class II, III, and ambulatory IV despite adequate medical treatment. This is particularly 
true for patients with LBBB with QRS duration 120-150 ms. After a detailed discussion with the team, it was decided to do implantation of a cardioverter-defibrillator with resynchronization function, equipped with remote monitoring (Biotronik, and Home monitoring). Date of implantation is June 19, 2014. Prescribed treatment after implantation: Perindopril $2 \mathrm{mg} /$ day (initial dose), further $4 \mathrm{mg} /$ day for 6 days, carvedilol $6.25 \mathrm{mg}$. 1 tab $\times 2$ times a day (with further increase to $25 \mathrm{mg} /$ day) for 14 days, spironolactone $50 \mathrm{mg}$. 1 cap $\times 1$ time/day for 5 days, enoxaparin sodium $0.6 \mathrm{ml} \times 2$ times a day, $\mathrm{p} / \mathrm{c}$ for 4 days, further acetylsalicylic acid $100 \mathrm{mg} \times 1$ time/ day for 4 days, rosuvastatin $10 \mathrm{mg}$. 1 tab $\times 1$ time/day for 7 days, cefuroxime $750 \mathrm{mg} \times 2$ times a day for 11 days, and chloropyramine $2.0 \mathrm{ml} / \mathrm{m}$ for 11 days.

\section{Follow-up}

ECG at discharge showed atrial-synchronized biventricular stimulation with HR-74 beats/min. QRS-120 ms. Routine follow-ups did not reveal any heart rhythm disturbances in the patient. Due to the fact that the patient was connected to the remote monitoring system, May 5, 2020, he was diagnosed with asymptomatic AF (Figures 1 and 2). First episode lasted $1 \mathrm{~min} 22 \mathrm{~s}$. On the following days of monitoring, episodes of AF were also recorded. The duration of the episodes ranged from $8 \mathrm{sec}$ to $12 \mathrm{~h} /$ day.

The patient received a doctor's consultation through video call, his risk of stroke was four when assessed using the $\mathrm{CHA}_{2} \mathrm{DS}_{2}$ VASc scale. In treatment, it was recommended to add antiarrhythmic drugs (amiodarone $600 \mathrm{mg}$ a day) and oral anticoagulants (rivaroxaban $20 \mathrm{mg} \times 1$ time/day).

Later periodic IEGM showed absence of AF (Figure 3). Such an important indicator as biventricular pacing was affected with the occurrence of AF in the patient. Namely BiV pacing before AF registration was $94 \%$, during AF it was $79 \%$, and after rhythm restoration this indicator was $98 \%$.

\section{Discussion}

In recent years, cardinal changes have occurred in all spheres of life associated with the spread of COVID-19 infection. Quarantine measures were applied in all countries to interrupt the chain of infection. Isolation at home, distance education and work, frequent hand washing, wearing masks, and other measures have been taken to "flatten the curve." This case report shows how we can shield patients with implanted heart devices from unnecessary inpatient visits, thereby reducing their risk of infection while preventing hospital congestion.
During this time of crisis, the load on the medical institution increased, the need arose to transform medical centers to the COVID-hospitals. The health workers faced the need to revise the methods of supervising their patients. Good solution in this case is remote monitoring by phone call. Patients with implanted heart devices are at high risk of death if infected with COVID-19. Thanks to the remote monitoring system, it became possible to give recommendations to such patients without resorting to face-to-face visits.

The world is witnessing an increase in operations on the implantation of heart devices associated with the expansion of the range of indications for implantation in the guidelines. These patients require constant medical supervision and can be consulted in an outpatient clinic without resorting to frequent hospitalizations. Patients with implanted heart devices need regular follow-up at least once every 6 months, as well as additional checkups if new symptoms occur or existing symptoms worsen [8].

The latest data on the increased mortality of patients with concomitant cardiac pathology from COVID-19 suggest the need to protect these patients in all possible ways, including replacing potentially dangerous offline visits with online consultations. Perhaps online consultation is not a complete substitute for face-to-face visits and there are many aspects that need to be worked on. Nevertheless, in today's unprecedented environment, remote consultations are the most reasonable solution [9].

Remote monitoring allows assessing not only physiological parameters such as heart rate and heart rate variability, but also the patient's activity and thoracic impedance, giving information about the presence of fluid. Remote monitoring of patients with implanted heart devices can, in today's challenging environment, become a tool to reduce the burden on hospitals and, most importantly, reduce the risk of complications in patients with newly diagnosed AF [10].

The debate over the anticoagulation of patients with subclinical AF diagnosed with the device continues. There is no clear recommendation on this in the guidelines [11]. There are several studies showing the risk of stroke in patients with device-detected AF. For example, in the ASSERT study subclinical AF lasting more than $24 \mathrm{~h}$ has been associated with an increased risk of stroke and systemic embolism [12]. In the TRENDS study, duration of AF or atrial flutter more than or equal to $5.5 \mathrm{~h}$ doubled the risk of thromboembolism [13]. In a study by Perino et al., it was found that patients taking oral anticoagulants had a lower risk of stroke. However, this was only true in patients with AF burden of more than $24 \mathrm{~h}$ [14]. Several ongoing large randomized trials are investigating the efficacy of new oral anticoagulants in preventing thromboembolic events in patients with subclinical device-detected AF. Perhaps the results of these studies will add clarity to this issue [15], [16]. In our case, when considering the 
issue of anticoagulation, both the burden of $\mathrm{AF}$ and the scores on the $\mathrm{CHA}_{2} \mathrm{DS}_{2}$ VASc scale were taken into account.

This approach is forced today and requires further improvement, but it will give impetus to the development of telemedicine for future use, even after the lifting of the restrictive measures associated with the pandemic.

\section{Conclusion}

The use of remote monitoring technologies allows continuous monitoring of the implanted system and patient indicators, several times reducing the number of scheduled and additional visits to the doctor. Remote monitoring also allows immediately identify or prevent emerging complications, which in some cases help to save the patient's life. The remote patient monitoring system became the most relevant during the COVID-19 pandemic, since patients were not able to come for routine examinations, but they had the opportunity to receive online recommendations.

\section{References}

1. Dilaveris PE, Kennedy HL. Silent atrial fibrillation: Epidemiology, diagnosis, and clinical impact. Clin Cardiol. 2017;40(6):413-8. http://doi.org/10.1002/clc.22667

PMid:28273368

2. Zhan C, Baine WB, Sedrakyan A, Steiner C. Cardiac device implantation in the United States from 1997 through 2004: A population-based analysis. J Gen Intern Med. 2008;23(Suppl 1):13-9. http://doi.org/10.1007/ s11606-007-0392-0

PMid:18095038

3. Mond HG, Proclemer A. The $11^{\text {th }}$ world survey of cardiac pacing and implantable cardioverter-defibrillators: Calendar year 2009-a world society of Arrhythmia's project. Pacing Clin Electrophysiol. 2011;34(8):1013-27. http://doi. org/10.1111/j.1540-8159.2011.03150.x PMid:21707667

4. Yegorov S, Goremykina M, Ivanova R, Good SV, Babenko D, Shevtsov A, et al. Epidemiology, clinical characteristics, and virologic features of COVID-19 patients in Kazakhstan: A nationwide retrospective cohort study. Lancet Reg Health Eur. 2021;4:100096. http://doi.org/10.1016/j.lanepe.2021.100096 PMid:33880458

5. January CT, Wann LS, Calkins H, Chen LY, Cigarroa JE, Cleveland JC Jr., et al. 2019 AHA/ACC/HRS Focused Update of the 2014 AHA/ACC/HRS Guideline for the Management of Patients With Atrial Fibrillation. Circulation. 2019;139:2502-12. http://doi.org/10.1161/CIRCULATIONAHA.118.038988

6. Kirchhof P, Benussi S, Kotecha D, Ahlsson A, Atar D, Casadei B, et al. 2016 ESC guidelines for the management of atrial fibrillation developed in collaboration with EACTS: The task force for the management of atrial fibrillation of the European society of cardiology (ESC) developed with the special contribution of the European heart rhythm association (EHRA) of the ESC Endorsed by the European stroke organization (ESO). Eur Heart J. 2016;38:2893-962. http://doi.org/10.1093/ eurheartj/ehw210

PMid:27567408

7. Zacà V, Marcucci R, Parodi G, Limbruno U, Notarstefano P, Pieragnoli $\mathrm{P}$, et al. Management of antithrombotic therapy in patients undergoing electrophysiological device surgery. Europace. 2015;17(6):840-54. http://doi.org/10.1093/europace/ euu357

PMid:25712980

8. NICE Guidance 106: Chronic Heart Failure in Adults: Diagnosis and Management; 2018. Available from: https://www.nice.org. uk/guidance/ng106. [Last accessed on 2020 Mar 30].

9. Chen T, Wu D, Chen H, Yan W, Yang D, Chen G, et al. Clinical characteristics of 113 deceased patients with coronavirus disease 2019: Retrospective study. BMJ. 2020;368:m1091. http://doi.org/10.1136/bmj.m1295

PMid:32234718

10. Cowie MR, Sarkar S, Koehler J, Whellan DJ, Crossley GH, Tang $\mathrm{WH}$, et al. Development and validation of an integrated diagnostic algorithm derived from parameters monitored in implantable devices for identifying patients at risk for heart failure hospitalization in an ambulatory setting. Eur Heart $\mathrm{J}$. 2013;34(31):2472-80. http://doi.org/10.1093/eurheartj/eht083 PMid:23513212

11. Noseworthy PA, Kaufman ES, Chen LY, Chung MK, Elkind MS Joglar JA, et al. Subclinical and device-detected atrial fibrillation: Pondering the knowledge gap: A scientific statement from the American heart association. Circulation. 2019;140(25):e944-63. http://doi.org/10.1161/CIR.0000000000000740 PMid:31694402

12. Van Gelder IC, Healey JS, Crijns HJ, Wang J, Hohnloser SH Gold MR, et al. Duration of device-detected subclinical atrial fibrillation and occurrence of stroke in ASSERT. Eur Heart J. 2017;38(17):1339-44. http://doi.org/10.1093/eurheartj/ ehx042 PMid:28329139

13. Glotzer TV, Daoud EG, Wyse DG, Singer DE, Ezekowitz MD Hilker C, et al. The relationship between daily atrial tachyarrhythmia burden from implantable device diagnostics and stroke risk: The TRENDS study. Circ Arrhythm Electrophysiol. 2009;2(5):474-80. http://doi.org/10.1161/CIRCEP.109.849638 PMid: 19843914

14. Perino AC, Fan J, Askari M, Heidenreich PA, Keung E, Raitt $\mathrm{MH}$, et al. Practice variation in anticoagulation prescription and outcomes after device-detected atrial fibrillation. Circulation. 2019;139(22):2502-12. http://doi.org/10.1161/ CIRCULATIONAHA.118.038988 PMid:30880434

15. Lopes RD, Alings M, Connolly SJ, Beresh H, Granger CB, Mazuecos JB, et al. Rationale and design of the apixaban for the reduction of thrombo-embolism in patients with devicedetected sub-clinical atrial fibrillation (ARTESiA) trial. Am Heart J. 2017;189:137-45. http://doi.org/10.1016/j.ahj.2017.04.008 PMid:28625370

16. Yang $\mathrm{Y}, \mathrm{Xu} \mathrm{F}$, Tong J, Cai $\mathrm{L}$, Jiang $\mathrm{W}$, Sheng $\mathrm{X}$, et al. Rationale and design of the evaluation of oral anticoagulation for reduction of thrombo-embolism in Chinese patients with device-detected subclinical atrial fibrillation (ART-CAF) trial: An open-label registry-based clinical trial. Cardiovasc Drugs Ther. 2018;32(4):389-96. http://doi.org/10.1007/ s10557-018-6807-9

PMid:30027309 